\title{
13. \\ ISKUSTVA \\ PSEUDOAUTOBIOGRAFSKOG ROMANA 20. STOLJEĆA: \\ ITALO ZVEVO I VLADAN DESNICA
}

\section{Luca Vaglio}

UDK: 821.131.1-31Svevo, I.-042.3:821.163.42-31Desnica, V. Prethodno priopćenje

Sažetak: Romani Zenova savest (La coscienza di Zeno, 1923.) Itala Zveva i Proljeća Ivana Galeba (1957.) Vladana Desnice predstavljaju neka od najvažnijih i najpoznatijih ostvarenja pseudoautobiografskog romana 20. veka u odgovarajućim književnim polisistemima. Glavne tematske, strukturne i poetičke karakteristike pomenutih dela analiziraju se u komparativnom ključu, da bi se uočile njihove sličnosti i razlike kao posebna ostvarenja pseudoautobiografskog romana. Međutim, istom analizom se prvenstveno ukazuje na činjenicu: 1) da je Vladan Desnica, odličan i zainteresovan poznavalac italijanske književnosti, mogao poznavati glavni Zvevov roman, koji je po objavljivanju doveo do međunarodnog uspeha autora, naročito među francuskim i engleskim književnicima (to je takozvani „slučaj Zvevo“), i 2) da se u Proljećima Ivana Galeba mogu primetiti razni mogući, važni tragovi prisustva i uticaja dela tršćanskog pisca, iako je zadarski autor ostvario originalno delo.

Ključne reči: pseudoautobiografski roman, moderni roman, komparativna književnost, čovek bez svojstava, južnoslovensko-italijanske književne veze

П utobiografski ili, upravo, po tačnijoj definiciji Franka D’Intina (Franco D'Intino), pseudoautobiografski roman (romanzo pseudoautobiografico) jeste jedna od konfiguracija koje je moderni roman dobio od svog nastanka u XVIII veku. Može se čak reći da je pseudoautobiografski roman jedan od tipova koji su najviše označili istoriju modernog romana od samih početaka. Najmanji zajednički imenitelj ovog tipa može se bolje definisati samo upoređujući takav roman sa autobiografijom u pravom smislu reči: autobiografija je žanr koji se bazira, u glavnim crtama, na podudaranju autora, pripovedača i protagoniste i među čijim karakteristikama se nalazi, pored svih posebnosti dokumentarnih žanrova, i fikcionalnost. ${ }^{1}$ Kao što još jednom ističe Franko D'Intino u svojoj monografiji o „modernoj

1 V. Franco D’Intino, L'autobiografia moderna. Storia forme problemi, Roma 2003. 
autobiografiji“, roman je žanr koji deli idealnu granicu sa autobiografijom, a „drugačija je vrsta fikcije pseudoautobiografskih romana, koji reprodukuju oblik pripovedanja baziran na autorovom pamćenju. U ovom slučaju, ime pripovedača podudara se sa imenom lika, ali ne i sa imenom autora". Između najreprezentativnijih dela ovog tipa romana može se navesti barem Mol Flanders (Moll Flanders, 1722.) Danijela Difoa (Daniel Defoe, 1660. - 1731.), budući da se ovim tekstom obično označava nastanak pseudoautobiografskog romana. Ipak, treba se odmah istaći da postoje razne konfiguracije ovog tipa romana i u tome dijahronijski, geografski i individualni činioci igraju, naravno, odlučujuću ulogu.

Romani Zenova savest (La coscienza di Zeno, 1923.) Itala Zveva (Italo Svevo, 1861. 1928.) i Proljeća Ivana Galeba (1957.; 2. dopunjeno izdanje 1960.) Vladana Desnice (1905. - 1967.) predstavljaju neka od najvažnijih i najpoznatijih ostvarenja pseudoautobiografskog romana 20. veka: u odgovarajućim književnim polisistemima. Poznato je da je zadarski pisac odlično poznavao italijanski jezik i italijansku književnost, kao što dokazuju spisi u kojima govori o toj književnosti i mnogobrojni prevodi sa tog jezika. ${ }^{3}$ Ta činjenica je toliko očigledna da je Sanja Roić, govoreći o piščevoj esejistici, rekla da su „pozivanja na mjesta iz talijanske kulture i književnosti česta, ima ih u tolikoj mjeri da talijanska kultura za autora poprima značenje strane referentne civilizacije i kulture par excellence “. ${ }^{4}$

Znajući sve što smo do sada rekli i dodajući da je glavni roman Itala Zveva veoma poznat i značajan i izvan granica italijanske književnosti i da ima, već na prvi pogled, nemali broj sličnosti sa glavnim romanom Vladana Desnice, nameću se dva pitanja: da li je zadarski pisac poznavao roman Zenova savest? Da li je ovo italijansko delo nekako uticalo na Proljeća Ivana Galeba? Ovde se ograničavamo na drugi Desničin roman da bismo što je više moguće smanjili polje istraživanja.

U potrazi za odgovorom na pomenuta pitanja počinjemo od nekih činjenica: prvo, Desnica ne pominje Zveva i njegova dela nigde i nikada, ni u jednom svom spisu bilo koje prirode (fikcionalne, pesničke, esejističke); drugo, u Desničinoj ličnoj biblioteci nije sačuvana nijedna Zvevova knjiga; ${ }^{5}$ tréé, nijedan od mnogobrojnih proučavalaca celokupnog opusa Vladana Desnice ne pominje Zveva, ni njegova dela. ${ }^{6}$

Ako je prva činjenica nepobitna, što se tiče druge može se ipak, teoretski, pretpostaviti da je Desnica mogao posedovati Zvevove knjige ili barem Zvevov glavni roman, a da je ta knjiga sada izgubljena, možda zbog Drugog svetskog rata. Treća činjenica, iako je i ona

$\overline{2}$ „Un tipo diverso di finzione è quello dei romanzi pseudoautobiografici, che riproducono la forma del racconto basato sulla memoria dell'autore. In questo caso il nome del narratore coincide con quello del personaggio, ma non con quello dell'autore", isto, 251.

3 V. Luka Valjo [Luca Vaglio], „Upotreba italijanskog jezika u delima Vladana Desnice“, Tvorci srpskog književnog jezika. Zbornik radova (ur. Vesna Matović i Miodrag Maticki), Beograd 2011., 247-265. U ovom članku se navodi i niz radova relevantnih za temu odnosa između Desnice i italijanske kulture, između kojih vredi da se pomene barem sledeći: Sanja Rorć, Stranci. Portreti s margine, granice i periferije, Zagreb 2006.

4 V. S. Roić, Stranci, 141.

5 V. Vladan Desnica, Hotimično iskustvo. Diskurzivna proza Vladana Desnice, knj. 2 (priredio i redigirao Dušan Marinković), Zagreb 2006., 251-280.

6 Veoma je značajno, pa će zbog toga ovde biti dovoljno kao primer iznesene teze, da nikada ne pominje Itala Zveva ni Krešimir Nemec, jedan od najznačajnijih proučavalaca Desničinog dela, posebno iz komparativne perspektive, v. Krešimir Nemec, Vladan Desnica, Zagreb 1988.; Isti, Povijest hrvatskog romana od 1945. do 2000. godine, Zagreb 2003. 
važna, ipak najmanje utiče na odgovor na pomenuta dva pitanja, zato što se jednostavno može desiti da nijedan proučavalac nije do sada mogao konstatovati sličnosti između dvaju autora, niti uticaj Zveva na Desnicu, a da pri tome oni ipak postoje.

Postoji još jedno pitanje na koje vredi pokušati odgovoriti: da li je Desnica uopšte poznavao Zveva i njegova dela, barem roman Zenova savest? Pored svega toga što smo malo pre rekli, možemo barem pretpostaviti sledeće: Vladan Desnica je mogao da sazna za opus tršćanskog pisca, i naročito za njegov glavni roman, usled takozvanog „slučaja Zvevo“ (1925.), dakle, samo dve godine nakon objavljivanja prvog izdanja tog dela (1923.). Tih godina se Zvevov uspeh ticao gotovo isključivo intelektualaca, posebno francuskih i engleskih, i upravo zahvaljujući nizu radova objavljenih u pohvalu Zveva prvenstveno u Francuskoj Desnica je mogao da sazna za italijanskog autora i njegov najpoznatiji roman. Uostalom, sama činjenica da je Zvevo bio iz Trsta i da se takođe u nekim tršćanskim novinama pisalo o njemu i o Zenovoj savesti može nas navesti - na osnovu geografske bliskosti sa Zadrom da pretpostavimo da je Desnica, koji je tada imao otprilike dvadeset godina, znao za njih.

Može se formulisati i treća pretpostavka, vezana za činjenicu da se pravi i definitivni uspeh Itala Zveva kod kritičara i, iznad svega, kod čitalaca dogodio posle Drugog svetskog rata, uprkos veoma slaboj distribuciji izdanja izdavača koji su do tada objavili Zenovu savest. $\mathrm{Na}$ to ukazuje čak i Euđenio Montale (Eugenio Montale), koji misli da je to „čudo, zaista, i suđeno da ima daljih posledica, tako da uključuje tršćanskog autora ne samo u osnovni kanon moderne pripovedačke proze, nego i u ograničenu grupu modernih klasika koje publika najviše čita i voli“" 7 Tih godina je Desnica uveliko ušao u petu deceniju svog života i počeo da radi na svom drugom, glavnom romanu. Izgleda da bi stvarno bilo teško da tako pripremljen i zainteresovan poznavalac italijanske književnosti nije uopšte znao za Zvevovo delo i da nije nikada imao u rukama njegove romane, premda se mora ponovo istaći da između knjiga koje pripadaju ličnoj zagrebačkoj biblioteci Vladana Desnice nema Zvevovih romana. Da li ih ima ili ih je bilo u Desničinoj kući u Islamu Grčkom (u Kuli Jankovića), treba se utvrditi. U stvari, ponavljamo, može se pretpostaviti da je Desnica posedovao glavni Zvevov roman ili čak i druge njegove romane, a da su te knjige izgubljene, možda tokom rata, ili ih je on možda čitao u nekoj biblioteci. Nažalost, to su za sada samo pretpostavke koje se ne mogu proveriti.

Što se tiče komparativne analize dvaju romana, Zenove savesti i Proljeća Ivana Galeba, lako se može konstatovati da između njih, na pripovedačkom i na tematskom nivou, postoje razne i očigledne razlike. Ipak, može se isto tako primetiti da postoje i razne sličnosti. Iako se one mogu objasniti mogućim zajedničkim uticajima ili činjenicom da dvojica pisaca, naročito ako žive u istom ili skoro $\mathrm{u}$ istom periodu, mogu doći do istih ili veoma sličnih rešenja i samostalno jedan od drugoga, ukazati na neke od tih sličnosti može biti korisno.

Pre svega, u oba romana glavni činilac radnje je otprilike isti, a to je ličnost pripovedača-protagoniste: sve u delu zavisi od njega i od njegovog života, što je logično i prilično prirodno za pseudoautobiografski roman, ali su slične i druge, važne karakteristike: radnju

„Un miracolo, davvero, e destinato a sviluppi ulteriori, sí da includere l'autore triestino non solo nel canone essenziale della narrativa moderna, ma nel ristretto drappello dei classici moderni ampiamente letti e amati dal pubblico", Gino Tellini, Svevo, Roma 2013., 256. 
romana ne sačinjavaju živahne, spoljašnje avanture Zena Kozinija (Zeno Cosini) ili Ivana Galeba, nego njihovi unutrašnji doživljaji, njihova raspoloženja, i to u određenim situacijama, onima koje su ostavile najjače tragove u njihovoj percepciji stvarnosti oko njih. Pored toga, obojica su okarakterisani i jakom ironijom, koja je često uperena prema njima samima, i skepticizmom i izvesnim otrežnjenjem prema raznim pojavama života (a otrežnjenje je toliko svojstveno Desničinom shvatanju stvarnosti da predstavlja naslov jedinog soneta koji je zadarski pisac napisao). Sve to čini da je osnovna konfiguracija obaju romana skoro istovetna, iako je ironija još jača u slučaju Zena Kozinija, a kod Ivana Galeba je veća težnja ka digresijama kao konstitutivnim elementima pripovedanja: radi se o nedoslednim, nekontinuiranim, prvenstveno unutrašnjim događajima, koji ne prate pretpostavljeni, dosledni vremenski i uzročni niz. Da se ta konfiguracija nikako ne podrazumeva kada se govori o pseudoautobiografskim romanima svedoči činjenica da su ranija dela koja pripadaju tom tipu često i u velikom delu zasnovana na putovanju, na pomeranju protagoniste, na ređanju gradova i zemalja u kojima su se oni nalazili, što dovodi do avanturističkog romana; ili se može desiti da se mesto nameće nad subjektom, što dovodi do autobiografske topografije. ${ }^{8}$

Ima i drugih sličnosti između Zveva i Desnice, pa vredi kratko ukazati barem na sledeće:

- važno je odmah istaći da su i Zeno Kozini i Ivan Galeb posebna ostvarenja lika nesposobnog čoveka, čoveka „bez svojstava“, koji ne ume da živi svoj život jednostavno i slobodno, nego je uvek pod dejstvom intelektualne aktivnosti, osećanja, duše; Zeno i Ivan pokazuju veoma slabu volju, ne mogu da pretvore svoje namere u delo, padaju iz nedoslednosti u nedoslednost;

- u Zenovoj savesti, na početku poglavlja 2 (Preambolo), može se čitati: „Vedere la mia infanzia? Più di dieci lustri me ne separano (...) („Da sagledam svoje detinjstvo? Više od deset dioptera odvajaju me od njega"10); izgleda da ove reči imaju precizan odjek u rečima kojima Ivan Galeb, u I poglavlju, određuje (otprilike) udaljenost između trenutka u kojem piše svoj „irealni dnevnik“ i detinjstva, kojim počinje njegov tekst: „Daleko doba [N. B.: misli se na 'djetinjstvo']! Između njega i današnjeg mene uvalilo se gotovo pedeset godina - pedeset godina koje se zovu čitav život“; ;1 štaviše, u poglavlju III (Pušenje) Zeno kaže koliko godina ima kada sastavlja svoj tekst: „Ne ho cinquantasette degli anni (...)“12 („Imam pedeset sedam godina“13), a Ivan Galeb piše svoj kada je otprilike bio $\mathrm{u}$ istim godinama;

- obojica pseudoautobiografa sastavljaju „opis“ svog života usled potrebe vezane za zdravlje, iako se radi o različitim situacijama - Zenovo je pisanje oblik terapije kojim želi da leči neurozu, Ivan piše dok je u bolnici zbog prilično neodređenog patološkog događaja (zbog povrede ruke), koji ipak nije psihološke prirode;

\footnotetext{
8 V. F. D'Intino, L'autobiografia moderna, 165-166.

9 Italo Svevo, La coscienza di Zeno [1923.], Isti, Romanzi (a cura di Mario Lavagetto con la collaborazione di Ferdinando Amigoni, Nunzia Palmieri e Arrigo Stara), Torino - Paris 1993., 510.

10 I. Zvevo, Zenova savest. Roman (prev. sa italijanskog Lela Matić), Beograd 2012., 20.

11 V. Desnica, Proljeća Ivana Galeba, Izabrana dela Vladana Desnice, knj. I-IV (prir. Stanko Korać i Jovan Radulović), Beograd - Priština 1993., 8.

12 I. Svevo, La coscienza di Zeno, 520.

13 Isti, Zenova savest, 31.
} 
- uprkos tome što je prethodno rečeno, jasno je da je psihoanaliza jako uticala na oba dela i odredila oblik pripovedanja u oba slučaja, iako je ona kod Zveva još jasnije prisutna, toliko da je i sama postala važna, karakteristična tema (naslov poslednjeg poglavlja ne može biti eksplicitniji: Psico-analisi, dakle: Psihoanaliza);

- u oba romana važna je metanarativna komponenta, iako je ona nešto naglašenija u Proljećima Ivana Galeba; Zenova i Ivanova ironija pogađa i njihovo autobiografsko pisanje, iako se još jednom to jače oseća u Desničinom delu; nije onda čudno što obojica pripovedača upotrebljavaju neke tipološke definicije da bi odredili svoj tekst: Zeno govori o „ispovestima“ (confessioni), ${ }^{14}$ o „autobiografiji“ (autobiografia) ${ }^{15}$ i u V poglavlju (Povest o mojoj ženidbi) ukazuje više puta na roman, u obliku poređenja, da bi objasnio situacije u kojima se nalazi, dok u XXXV poglavlju Ivan govori o ,irealnom dnevniku“ i o ,jednom neosmišljenom životopisu“; ${ }^{16}$ pored toga, u Zvevovom romanu Doktor S., kome se Zeno obraća da se leči, takođe daje neke veoma zanimljive definicije rukopisa svog pacijenta, pa govori o „noveli“ (novella), ${ }^{17}$ još jednom o „autobiografiji“ (autobiografia) i, najzad, $\mathrm{O}$ „uspomenama“ (memorie),${ }^{18}$ a činjenica da se te definicije nalaze na samom početku teksta čini ih još značajnijim i izričitijim;

- jedan od elemenata koji može navesti na pretpostavku da je Desnica mogao da pročita Zenovu savest $\mathrm{i}$ da je trag toga, možda nehotičan, ostao u njegovim Proljećima Ivana Galeba jeste da Zeno svira violinu, baš kao i Ivan; to što je u Desničinom romanu pripovedač-protagonista čak profesionalni muzičar, virtuoz violine, može ukazati na činjenicu da je zadarski pisac namerno mogao da razvija temu koja se nalazi u Zvevovom delu; vredi napomenuti i to što se u Zenovoj savesti tema violine poziva na stvarni podatak iz Zvevove biografije (i pisac i njegov brat svirali su taj instrument);

- detinjstvo je veoma važna tema u oba romana, iako se u Proljećima Ivana Galeba još više govori o njemu; značaj te teme može se dovesti uopšte u vezu sa psihoanalizom, ali to ne umanjuje njenu relevantnost za teze koje se ovde izlažu;

- smrt je središnja tema obaju romana, ona je sveprisutna u Zenovim i u Ivanovim mislima i razmišljanjima, kao što i sami priznaju, pa određuje i barem delimično karakteriše i pripovedanje i tematski nivo obaju dela;

- najzad, u Zenovoj savesti postoji važan lajtmotiv, a to je proleće, što se pojavljuje u raznim delovima romana i spojeno je sa izražavanjem raspoloženja pripovedača-protagoniste, ponekad sa poetskom notom, a svakako uvek u pozitivnoj konotaciji; značenje teme proleća u Zvevovom delu izlazi na svetlo dana, na primer, kada se pominje da se upravo u to godišnje doba, kao što ističe pripovedač, završava veza sa Karlom (Carla), njegovom ljubavnicom („Anche quella era una giornata pregna della nuova primavera dolce e lumi-

14 Isti, La coscienza di Zeno, 865 .

15 Isto, 580.

16 V. Desnica, Proljeća Ivana Galeba, 200.

17 U srpskom prevodu Zvevovog romana, koji se ovde upotrebljava, reč novella je prevedena rečju priča (v. I. Zvevo, Zenova savest, 19); iako bi precizniji prevod bio novela, u svakom slučaju ne gubi se jako metanarativno pozivanje ovog pasusa.

18 I. Svevo, La coscienza di Zeno, 509. 
nosa $\left.{ }^{(19}\right)$, ali su mogući mnogi drugi primeri; nije potrebno posebno istaći da je to jedna od ključnih tema glavnog romana Vladana Desnice, kao što se vidi po samoj činjenici da se nalazi u naslovu dela, ali se takođe radi, uz smrt, o veoma važnoj temi u celokupnom Desničinom opusu i u njegovom shvatanju stvarnosti, u kojima na simboličnom nivou predstavlja upravo suprotnost smrti.

Veoma je zanimljiva još jedna sličnost između tršćanskog i zadarskog pisca: za francuski prevod svog glavnog romana Zvevo je predviđao niz posebnih autografskih varijanata, ${ }^{20}$ pa znamo da je upravo istu nameru imao i Desnica za italijanski prevod svog drugog romana. $^{21}$

$\mathrm{Na}$ osnovu podataka iznetih do sada, ne možemo još zaključiti sa sigurnošću da je Desnica poznavao Zveva i njegov glavni roman, ali ipak imamo nekoliko činjenica vezanih za njihova posebna ostvarenja pseudoautobiografskog romana, koje sugerišu da se pretpostavke izložene na početku ne mogu smatrati potpuno neosnovanim i da vredi dalje istraživati odnos između dvojice važnih predstavnika modernog romana. Desnica je napisao delo koje poseduje jasnu originalnost iz raznih vidova, originalnost koja može da vredi i na evropskom nivou; međutim, ako se utvrdi njegova veza sa Zvevovim romanom, ta činjenica bi mogla da drugačije osvetli Desničinu radionicu i da otvori novi put u proučavanju odnosa između južnoslovenskih književnosti i italijanske književne tradicije.

\section{$\cos$}

\section{EXPERIENCES OF THE PSEUDO-AUTOBIOGRAPHICAL NOVEL of the $20^{\mathrm{TH}}$ Century. Italo Svevo and Vladan Desnica}

Italo Svevo's novel Zeno's conscience (La coscienza di Zeno, 1923) and Vladan Desnica's The Springs of Ivan Galeb (Proljeća Ivana Galeba, 1957) are among the most notable pseudo-autobiographical novels of the $20^{\text {th }}$ century in their respective literary polysystems. A comparative analysis of the chief thematic, structural and poetical features of these works is provided to highlight their similarities and differences as instances of a pseudo-autographical novel. However, the analysis primarily shows that 1) Vladan Desnica, a great and enthusiastic connoisseur of Italian literature, could have been familiar with Svevo's magnum opus, a book which gave its author international success, particularly among French and English authors (the so-called Svevo case) and 2) that The Springs of Ivan Galeb shows what might be important signs of being influenced by the writer from Trieste, although the novel by the writer from Zadar is an original accomplishment.

Key words: pseudo-autobiographical novel, modern novel, comparative literature, man without qualities, South Slavic-Italian literary relations

19 Isto, 740; „I ovaj je dan bio ispunjen novim prolećem, blagim i blistavim“, Isti, Zenova savest, 285.

20 V. G. Tellini, Svevo, 141.

21 V. Luca VAgLio, „Le primavere di Ivan Galeb di Vladan Desnica: l'opera, la sua genesi, la nuova edizione italiana“, V. Desnica, Le primavere di Ivan Galeb (nuova ed. italiana a cura di Luca Vaglio, trad. di Giovanni Bensi e Luca Vaglio), Roma 2016., 13-14. 


\section{cos}

\section{Literatura}

Vladan Desnica, Hotimično iskustvo. Diskurzivna proza Vladana Desnice, knj. 2 (priredio i redigirao Dušan Marinković), Zagreb 2006.

Vladan Desnica, Le primavere di Ivan Galeb (nuova ed. italiana a cura di Luca Vaglio, trad. di Giovanni Bensi e Luca Vaglio), Roma 2016.

Vladan Desnica, Proljeća Ivana Galeba [1957.; 2. dopunjeno izd. 1960.], Izabrana dela Vladana Desnice, knj. I-IV (prir. Stanko Korać i Jovan Radulović), Beograd - Priština 1993.

Franco D’Intino, L'autobiografia moderna. Storia forme problemi, Roma 2003.

Krešimir Nemec, Povijest hrvatskog romana od 1945. do 2000. godine, Zagreb 2003.

Krešimir Nemec, Vladan Desnica, Zagreb 1988.

Sanja RoIć, Stranci. Portreti s margine, granice i periferije, Zagreb 2006.

Italo Svevo, La coscienza di Zeno [1923.], Isti, Romanzi (a cura di Mario Lavagetto con la collaborazione di Ferdinando Amigoni, Nunzia Palmieri e Arrigo Stara), Torino - Paris 1993., 507-895.

Gino Tellini, Svevo, Roma 2013.

Luca Vaglio, „Il filo sfilacciato della narrazione. Osservazioni su Proljeća Ivana Galeba di Vladan Desnica“, Europa Orientalis, XXVII/2008., 179-208.

Luca VAGLIO, „Le primavere di Ivan Galeb di Vladan Desnica: l'opera, la sua genesi, la nuova edizione italiana", VladAn Desnica, Le primavere di Ivan Galeb (nuova ed. italiana a cura di Luca Vaglio, trad. di Giovanni Bensi e Luca Vaglio), Roma 2016., 5-16.

Luka VAljo [Luca VAgLio], „Upotreba italijanskog jezika u delima Vladana Desnice“, Tvorci srpskog književnog jezika. Zbornik radova (ur. Vesna Matović i Miodrag Maticki), Beograd 2011., 247-265.

Italo Zvevo, Zenova savest. Roman (prev. sa italijanskog Lela Matić), Beograd 2012. 